\title{
Clinical Experience of Fluroscopy Guided Percutaneous Transpedicular Biopsy of Spinal Lesion
}

\author{
Suman Rijal, ${ }^{1}$ Pankaj Raj Nepal,, ${ }^{2}$ Manita Raut, ${ }^{1}$ Dinesh Nath Gongal ${ }^{1}$
}

'Department of Neurosurgery, Upendra Devkota Memorial National Institute of Neurological and Allied Sciences, Bansbari, Kathmandu, Nepal, ${ }^{2}$ Department of Neurosurgery, B and C Medical College and Teaching Hospital, Birtamod, Jhapa, Nepal.

\section{ABSTRACT}

Introduction: The diagnosis of the spinal lesions often puts the clinician in dilemma. The definite diagnosis is obviously needed for the proper management of the disease. The wrong diagnosis not only imposes the adverse effects, but sometimes may lead to the disabling conditions and even prove to be life threatening. This study is aimed at evaluating the need of fluoroscopy guided percutaneous transpedicular biopsy for establishing the proper diagnosis and find the diagnostic yield.

Methods: This is the descriptive cross-sectional study conducted over the period of 10 years in the Upendra Devkota Memorial National Institute of Neurological and Allied Sciences among the patients who underwent transpedicular biopsy for various spinal lesions.

Results: Among the 77 cases, 38 (49\%) of the lesions on MRI were single level whereas $39(51 \%)$ of the lesions were multiple. Most of the lesions were diagnosed as the non-tubercular infection 30 (42\%), followed by the osteoporotic fractures and malignancy in 18 (25\%) and $15(21 \%)$ respectively. The sensitivity and specificity of the radiology with the background of clinical scenario was $79.5 \%$ and $90.9 \%$ respectively. The diagnostic yield of the biopsy was $93.5 \%$.

Conclusions: The transpedicular biopsy of the spinal lesion is the must for the proper diagnosis and treatment plan of such cases. The change in the diagnosis after biopsy is often possible which will drastically alter the treatment plan.

Keywords: fluoroscopy guided; metastasis; spinal lesions; transpedicular biopsy; Tuberculosis.

\section{INTRODUCTION}

Diagnosis of the various spinal lesions has been increasing due to the upfront imaging technology and the reach of patients to the medical care. Uncertainty in diagnosis may lead to the wrong treatment in those patients. ${ }^{1}$ Definitive histopathological diagnosis of spinal lesion is eminent to standardized management strategy.

There has been extensive study regarding the efficacy of the transpedicular vertebral body biopsy (TPVB) of the spinal lesions in the past. ${ }^{2,3}$ However, there are sparse literature in the setting of developing country like Nepal.
With the aim to establish the efficacy of biopsy of the various spinal lesions by means of TPVB, this study has been conducted in the single tertiary neurosurgical care center.

\section{METHODS}

This is a descriptive cross-sectional study conducted

Correspondence: Dr. Suman Rijal, Department of Neurosurgery, Upendra Devkota Memorial National Institute of Neurological and Allied Science, Bansbari, Kathmandu, Nepal. Email: dr.rijalsuman@gmail.com, Phone: +977-9841315945. 
in Upendra Devkota Memorial National Institute of Neurological and Allied Sciences, Bansbari, Kathmandu, Nepal among 77 patients who underwent TPVB of spinal lesion during a period of 10 years from 2008-2017. Ethical approval was taken from UDMNINAS, IRC. Patient who underwent open biopsy or decompression of cord were excluded. Age, gender, site of lesion, clinical findings, etiology, tuberculin test, radiological diagnosis, histopathological examination (HPE) reports, complication and mortality data were retrieved from medical archives. Sensitivity and specificity of radiological finding and diagnostic yield of TPVB was analyzed.

\section{RESULTS}

There were 77 patients included in the study. Among them $32(42 \%)$ were male and $45(58 \%)$ were female. The mean age was 54.43 (SD 16.89) years. Of all the cases, in $38(49 \%)$ patients the lesion was single and in $39(51 \%)$ cases the lesions were multiple. Of the multiple lesions, 32 (82\%) lesions were contiguous and $7(18 \%)$ were skip lesions (Table 1$)$.

\begin{tabular}{|lcc|}
\hline $\begin{array}{l}\text { Table 1. Lesion distribution } \\
\text { multiplicity. }\end{array}$ & according to the \\
\hline S.N & Multiplicity of Lesion \\
1. Single & $38(49 \%)$ \\
& \\
2 & Multiple & $39(51 \%)$ \\
& $\begin{array}{l}\text { a. Contiguous lesion } \\
\text { b. Skip lesions }\end{array}$ & $32(82 \%)$ \\
\end{tabular}

Moreover, most of the lesions that involved the vertebral body was confined to lumbar vertebra $84(69.4 \%)$ with few distributed to the thoracic region $34(28.1 \%)$ and sacral region $3(2.5 \%)$ (Figure 1$)$.

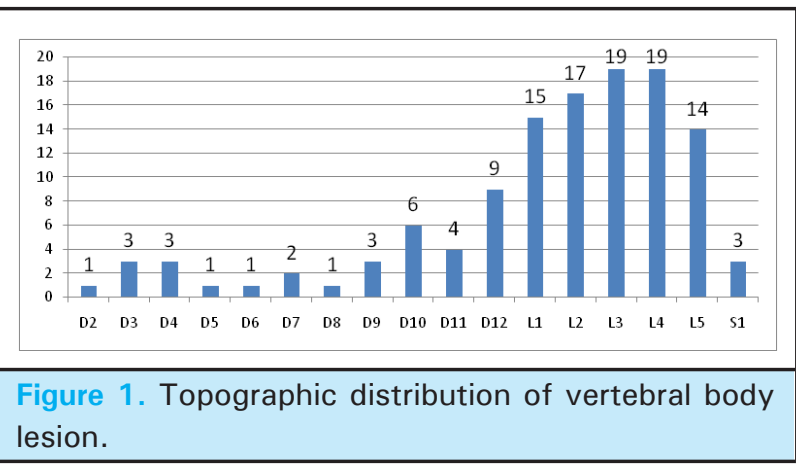

Among the 19 cases with disc space involvement, 17 cases had involvement of the intervertebral disc space at the lumbar region. Of all the vertebral biopsy undertaken, 32 (42\%) were proved to be non-tubercular spondylodiscitis followed by osteoporotic fracture 18 (25\%) and metastatic lesion 15 (21\%) respectively. Moreover, tuberculosis was revealed in $9(12 \%)$ of the biopsy (Figure 2).

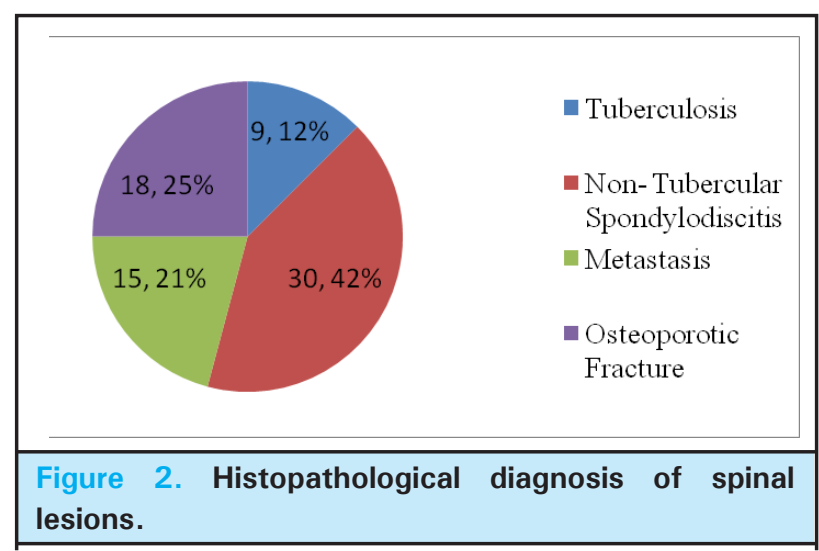

Only 7 out of 26 with tuberculin test positive were proved to be tuberculosis by HPE. Also, 2 cases out of 51 with negative tuberculin test came to be tuberculosis in HPE. The sensitivity and specificity of tuberculin test in diagnosing spinal tuberculosis was $77.80 \%$ and $72.10 \%$ respectively.

Radiological diagnosis of vertebral infection was refuted by TPVB among $20.5 \%$. Whereas, radiological diagnosis of vertebral infection was verified by TPVB in $79.5 \%$ of the cases. The sensitivity and specificity of the radiology in diagnosing infection were $79.50 \%$ and $90.90 \%$ respectively (Table 2 ).

\begin{tabular}{|c|c|c|c|c|}
\hline \multicolumn{5}{|c|}{$\begin{array}{l}\text { Table 2. A } \\
\text { infection. }\end{array}$} \\
\hline \multirow{4}{*}{$\begin{array}{l}\text { Radiological } \\
\text { Infection }\end{array}$} & & \multicolumn{2}{|c|}{ HPE Proven Infection } & \multirow[t]{2}{*}{ Total } \\
\hline & & Positive & Negative & \\
\hline & Negative & 30 & 8 & 38 \\
\hline & Positive & 3 & 31 & 34 \\
\hline Total & & 33 & 39 & 72 \\
\hline
\end{tabular}

Out of 17 radiological suspicion of metastasis (Mets), 11 were ascertained histopathologically. Similarly, out of 27 radiological suspicion of pyogenic infection, 17 were ascertained histopathologically to be same. However, only 2 cases were proved to be tubercular, out of the 8 radiological suspicions. Moreover, 12 out of 17 cases suspected to have osteoporotic fracture were proved by TPVB. Radiology was inconclusive to report specific diagnosis in 8 cases. Among those undetermined cases, 5 cases were proved to be of 
pyogenic infection, 2 were proved to be metastasis.

However, HPE was reported normal in one case.

Of the 77 total cases, 5 cases had normal finding in

HPE (Table 3). The diagnostic yield of TPVB was $93.5 \%$.

\begin{tabular}{|c|c|c|c|c|c|c|c|}
\hline & \multicolumn{7}{|c|}{ Histopathology reports } \\
\hline \multirow{7}{*}{$\begin{array}{ll}\text { Initial } & \text { radiological } \\
\text { diagnosis } & \end{array}$} & & Normal & Pyogenic & TB & Mets & Osteoporotic & Total \\
\hline & Mets & 2 & 1 & 0 & 11 & 3 & 17 \\
\hline & Pyogenic & 1 & 17 & 6 & 0 & 3 & 27 \\
\hline & TB & 0 & 6 & 2 & 0 & 0 & 8 \\
\hline & Osteoporotic & 1 & 1 & 1 & 2 & 12 & 17 \\
\hline & Undetermined & 1 & 5 & 0 & 2 & 0 & 8 \\
\hline & Total & 5 & 30 & 9 & 15 & 18 & 77 \\
\hline
\end{tabular}

Among all the cases, we experienced hemothorax as the complication of TPVB at thoracic level in one patient, which was managed with chest tube insertion. No other complications were noted. There was no mortality in our series.

\section{DISCUSSION}

There has been extensive study regarding the efficacy of the TPVB of the spinal lesions in the past. ${ }^{2,3}$ As of our study, the uncertainty of the diagnosis only by means of clinical and radiological findings has been found in the study done by Gupta et al. ${ }^{1}$ Such kind of uncertain diagnosis may lead to the wrong treatment in those patients. The study done by Smith et al., showed that $\mathrm{MRI}$ findings of the tubercular origin are similar to that of neoplasms. ${ }^{4}$ Furthermore, the need of establishing the diagnosis by biopsy has also been emphasized by many other authers. ${ }^{1,5}$ The various limitations that differentiate the malignant pathological fracture and the osteoporotic fractures has been highlighted by Pozzi et al. ${ }^{6}$

Our study demonstrated all tubercular looking like spinal lesions in the MR are not always tubercular. Rather, few lesions came out to be metastatic and osteoporotic fractures along with few being the infectious too and vice-versa. The study done by Janardhana also showed that $17 \%$ of the cases had change in diagnosis after the biopsy. ${ }^{7}$ We found that the tuberculin test is not very specific and sensitive in diagnosing the tubercular lesion. This fact clearly demonstrates the need of biopsy in any spinal lesions. The biopsy has got high sensitivity in diagnosing the malignancy and the infection. Rivas et al. had found the sensitivity and specificity of the biopsy as $86 \%$ and $100 \%$ respectively. ${ }^{8}$ In our study, the sensitivity and specificity of the radiology was $79.5 \%$ and $90.90 \%$ respectively. Moreover, the diagnostic yield of the transpedicular biopsy was $93.5 \%$.

Various complications of the transpedicular biopsy have been reported in the literature and have been estimated from 0 to $7.6 \% .^{2,9}$ The older paper had reported the complication rate up to $26 \% .{ }^{10}$ In our study only one patient who had thoracic vertebra transpedicular biopsy had hemothorax which was successfully managed with the chest tube insertion. No other complications were noted in our study. CT or the fluoroscopy has made this invasive procedure more safer and accurate. ${ }^{11,12}$

\section{CONCLUSIONS}

The fluoroscopy guided TPVB is safe and efficacious tool to target the spinal lesion with high accuracy. Prospective study including larger population is recommended to support this conclusion.

\section{Conflict of Interest: None.}




\section{REFERENCES}

1. Gupta RK, Agarwal P, Rastogi H, Kumar S. Phadke RV, Krishnani N. Problems in distinguishing spinal tuberculosis from neoplasia on MRI. Neuroradiology. 1996;38(Suppl 1):S97-104. [ PubMed ]

2. Bender CE, Berquist TH, Wold LE. Imaging-assisted percutaneous biopsy of the thoracic spine. Mayo Clin Proc. 1986;61:942-50. [ $\underline{\text { PubMed }}$ | Full Text]

3. Renfrew DL, Whitten CG, Wiese JA, El-Khoury GY, Harris KG. CT-guided percutaneous transpedicular biopsy of the spine. Radiology. 1991;180:574-6. [PubMed | Full Text | DOI ]

4. Smith AS, Weinstein MA, Mizushima A, Coughlin B, Hayden SP, Lakin MM, et al. MR imaging characteristics of tuberculous spondylitis vs vertebral osteomyelitis. Am J Roentgenol. 1989;153:399-405. [마bMed | Full Text | DOI]

5. Ahmadi J, Bajaj A, Destian S, Segall HD, Zee CS. Spinal tuberculosis: a typical observations at MR imaging. Radiology. 1993;189(2):489-93. [라bMed | Full Text | DOI]

6. Pozzi G, Garcia PC, Stradiotti P, Tien TV, Luzzati A, Zerbi A. Diffusion weighted MR imaging in differentiation between osteoporotic and neoplastic vertebral fractures. Eur Spine J. 2012;21(Suppl 1):S123-S127. [ubMed | Full Text | DOI]
7. Aithala JP. Role of Percutaneous Image Guided Biopsy in Spinal Lesions: Adequacy and Correlation with MRI Findings. J Clin Diagn Res. 2016;10(8): RC11-RC15. [PubMed | Full Text | DOI]

8. Rivas A, Caceres E, Ubierna M, Llado A, Ramirez M, Salo G, et al. Reliability, Sensitivity, Specificity and Safety of Computed Tomography-guided Percutaenous Vertebral Biopsies. Rev Ortop Traumatol (Madr). 2007;51:245-55. [Full Text]

9. Laredo JD, Bard M. Thoracic spine: percutaneous trephine biopsy. Radiology. 1986;160:485-489. [PubMed | Full Text | DOI]

10. Fyfe I, Henry APJ, Mulholland RC. Closed vertebral biopsy. J Bone Joint Surg. 1983;65:140-3. [PubMed ]

11. Peh WCG. CT guided percutaneous biopsy of spinal lesions. Biomed Imaging Interv J. 2006;2(3):e25. [PubMed | Full Text | DOI]

12. Nourbakhsh A, Grady JJ, Gardges KJ. Percutaneous spine biopsy: a meta-analysis. J Bone Joint Surg Am. 2008;90(8):1722-25. [PubMed | Full Text | DOI]

The Author(s) 2018.

This work is licensed under a Creative Commons Attribution 4.0 International License. The images or other third party material in this article are included in the article's Creative Commons license, unless indicated otherwise in the credit line; if the material is not included under the Creative Commons license, users will need to obtain permission from the license holder to reproduce the material. To view a copy of this license, visit http://creativecommons.org/licenses/by/4.0/ 